\title{
Evaluating the removal of pigs from a group and subsequent floor space allowance on the growth performance of heavy-weight finishing pigs 1
}

\author{
J. R. Flohr, * M. D. Tokach,* J. M. DeRouchey, ${ }^{*}$ J. C. Woodworth, * R. D. Goodband, * and S. S. Dritz ${ }^{\dagger 2}$ \\ *Department of Animal Sciences and Industry, College of Agriculture, \\ Kansas State University, Manhattan 66506-0201; and $†$ Department of Diagnostic \\ Medicine/Pathobiology, College of Veterinary Medicine, Kansas State University, Manhattan 66506-0201
}

\begin{abstract}
A total of 1,092 finishing pigs (initially $36.3 \mathrm{~kg}$ ) were used in a $117-\mathrm{d}$ study to evaluate the impact of initial floor space allowance and removal strategy on the growth of pigs up to $140 \mathrm{~kg} \mathrm{BW}$. There were 4 experimental treatments with 14 pens per treatment. The first treatment provided $0.91 \mathrm{~m}^{2}$ per pig (15 pigs/pen). The other 3 treatments initially provided $0.65 \mathrm{~m}^{2}$ per pig (21 pigs/pen) with 3 different removal strategies. The second treatment $(2: 2: 2)$ removed the 2 heaviest pigs from pens on $\mathrm{d} 64,76$, and 95 when floor space allowance was predicted to be limiting. Treatment 3 (2:4) removed the 2 heaviest pigs on $d$ 76 and the 4 heaviest pigs on d 105. Treatment 4 (6) removed the heaviest 6 pigs on $d 105$. All pigs remaining in pens after removals were fed to $\mathrm{d} 117$. Overall (d 0 to 117), pigs initially provided $0.91 \mathrm{~m}^{2}$ of floor space had increased $(P<0.05)$ ADG compared to pigs in pens on the 2:4 or 6 removal strategy, but ADG was not different compared with pigs on the 2:2:2 removal strategy. Total BW gain per pen was greater $(P<0.05)$ for pens initially stocked at $0.65 \mathrm{~m}^{2}$ compared to pens

initially stocked at $0.91 \mathrm{~m}^{2}$. Feed usage per pen was less $(P<0.05)$ for pens initially stocked at $0.91 \mathrm{~m}^{2}$ compared to pens initially providing $0.65 \mathrm{~m}^{2}$ of floor space and on removal strategies; however, feed usage per pig was greater $(P<0.05)$ for pigs initially stocked at $0.91 \mathrm{~m}^{2}$ compared to pigs initially stocked at $0.65 \mathrm{~m}^{2}$ and on removal strategies. Feed usage, on a pig or pen basis, was less $(P<0.05)$ for pigs on the 2:2:2 removal strategy compared to pigs on the 2:4 or the 6 removal strategy. Income over feed and facility cost (IOFFC) was less $(P<0.05)$ for pigs initially provided $0.91 \mathrm{~m}^{2}$ compared to pigs initially provided $0.65 \mathrm{~m}^{2}$ and on removal strategies. Also, IOFFC was less $(P<0.05)$ for pigs on the 2:2:2 compared to the $2: 4$ and 6 removal strategies. In conclusion, increasing the floor space allowance or the time points at which pigs are removed from the pen improved the growth of pigs remaining in the pen; however, IOFFC may be reduced because fewer pigs are marketed from each pen (pigs stocked at $0.91 \mathrm{~m}^{2}$ throughout the study) or from reducing total weight produced (2:2:2 removal strategy).
\end{abstract}

Key words: finishing pig, floor space, late finishing, removals

(C) 2016 American Society of Animal Science. All rights reserved.

J. Anim. Sci. 2016.94:4388-4400 doi:10.2527/jas2016-0407

\section{INTRODUCTION}

Reducing the variation in BW of pigs marketed to commercial abattoirs is a ubiquitous goal of swine producers because of the economic incentives tied to marketing animals within a specified weight range. One common practice is to market the heaviest pigs

\footnotetext{
${ }^{1}$ Contribution number 16-218-J from the Kansas Agricultural Experiment Station, Manhattan, KS 66506-0210

${ }^{2}$ Corresponding author: dritz@ksu.edu

Received February 23, 2016.

Accepted July 5, 2016.
}

in a group prior to marketing the entire group. This provides additional time for lighter-weight pigs that remain to reach a more desirable $\mathrm{BW}$.

Following the removal of pigs from a group, increased growth of the pigs remaining is typically observed (Woodworth et al., 2000; Jacela et al., 2009). DeDecker et al. (2005) concluded that the improved growth performance of pigs was the result of increased feed intake from increased pen resources that were provided after pigs within the group were removed. One resource that has clearly been shown to impact growth of finishing pigs is floor space allowance (Gehlbach et al., 1966; Jensen et al., 1973; Moser et 
al., 1985). Gonyou et al. (2006) developed floor space prediction equations for $\mathrm{ADG}$ and $\mathrm{ADFI}$ on the basis of a review of published literature. A decade later it is still recognized as the most commonly used predictor of finishing pig growth based on floor space allowance because of its use of a percentage change in ADG and ADFI, which is easily translated across a wide variety of genetic, health, and environmental scenarios that can impact growth. Interestingly, these prediction equations were developed using previously published research that evaluated the influence of floor space allowance on pigs up to approximately $110 \mathrm{~kg}$, which is well below current BW targets for finishing pigs.

The objectives of this study were to evaluate initial stocking density and marketing removal strategies on the growth of pigs remaining in the pen until market as well as the economic implications of the experimental treatments. Additionally, this study was designed to help validate whether the use of the prediction equations proposed by Gonyou et al. (2006) is applicable for heavier-weight finishing pigs.

\section{MATERIALS AND METHODS}

This experiment was conducted in a commercial wean-to-finish facility in central Iowa. This study was approved by and conducted in accordance with the guidelines of the Kansas State University Institutional Animal Care and Use Committee.

\section{Experimental Design}

The experiment was conducted as a generalized randomized design, with sex acting as a main factor and a total of 7 pens per experimental treatment randomly assigned within each sex, providing a total of 14 pens per experimental treatment. Four experimental treatments were compared: 1) initial floor space allowance of $0.91 \mathrm{~m}^{2}$ (15 pigs/pen) with no pigs removed from pens, designed to provide enough space for pigs to be above their predicted requirement until $140 \mathrm{~kg}$ (control); 2) initial floor space allowance of $0.65 \mathrm{~m}^{2}$, with the 2 heaviest pigs removed when average $\mathrm{BW}$ was high enough to drop the $k$ coefficient below its predicted optimal threshold ( 0.0336 ; as calculated by the equation $k=$ floor space, $\mathrm{m}^{2} / \mathrm{BW}^{0.67}$ ) proposed by Gonyou et al. (2006), with the average weights targeted being $83 \mathrm{~kg}\left(0.65 \mathrm{~m}^{2}\right), 97 \mathrm{~kg}$ $\left(0.72 \mathrm{~m}^{2}\right)$, and $114 \mathrm{~kg}\left(0.80 \mathrm{~m}^{2}\right)$, respectively, which corresponded to removals conducted on d 64, 76, and 95 of the study (2:2:2 strategy); 3 ) initial floor space allowance of $0.65 \mathrm{~m}^{2}$ with the 2 heaviest pigs removed at an average BW of $109 \mathrm{~kg}$ and the 4 heaviest pigs removed when average BW reached $127 \mathrm{~kg}$ with removals conducted on d 76 and 105 (2:4 strategy); and 4) initial floor space
Table 1. Removal strategies based on experimental treatments 1

\begin{tabular}{lcccc}
\hline \hline & \multicolumn{4}{c}{ Initial floor space, $\mathrm{m}^{2}$} \\
\cline { 2 - 5 } & 0.91 & \multicolumn{4}{c}{0.65} & 0.65 & 0.65 \\
\cline { 2 - 5 } Day & \multicolumn{4}{c}{ Removal strategy ${ }^{2}$} \\
\cline { 2 - 5 } d 0 & $0(15)$ & $0(21)$ & $0(21)$ & $0(21)$ \\
d 64 & $0(15)$ & $2(19)$ & $0(21)$ & $0(21)$ \\
d 76 & $0(15)$ & $2(17)$ & $2(19)$ & $0(21)$ \\
d 95 & $0(15)$ & $2(15)$ & $0(19)$ & $0(21)$ \\
d 105 & $0(15)$ & $0(15)$ & $4(15)$ & $6(15)$ \\
d 117 & $15(0)$ & $15(0)$ & $15(0)$ & $15(0)$ \\
\hline
\end{tabular}

${ }^{1} \mathrm{~A}$ total of 1,092 pigs (PIC $359 \times$ Genetiporc F25 females; initial BW $=$ $36.3 \mathrm{~kg}$ ) were used in a 117-d study to determine the influence of initial floor space allowance and removal strategy on growth performance. There were either 15 or 21 pigs per pen and 14 pens ( 7 barrow and 7 gilt pens) per treatment.

${ }^{2}$ Pigs initially provided $0.65 \mathrm{~m}^{2}$ of floor space were removed using 3 different strategies: 2:2:2 signifies pens where the 2 heaviest pigs on $\mathrm{d} 64$, 76 , and 95 were removed; 2:4 represents pens where the heaviest 2 pigs were removed on $\mathrm{d} 76$ and the 4 heaviest pigs were removed on $\mathrm{d} 105$; and 6 represents pens where the heaviest 6 pigs were removed on d 105. Values in parentheses represent the calculated number of pigs left following the experimental marketing strategies.

allowance of $0.65 \mathrm{~m}^{2}$ with the 6 heaviest pigs removed when average BW reached $127 \mathrm{~kg}$, which correlated to d 105 of the study ( 6 strategy). Table 1 provides a timeline of marketing events that occurred by experimental treatment throughout the length of the study. Prior to initiation of the study, all pens were stocked with 21 pigs $\left(0.65 \mathrm{~m}^{2}\right)$. Pens were blocked by sex and were randomly allotted to treatments within each block. The number of pigs per pen was adjusted after allotment to experimental treatments to reflect the desired initial stocking density. Pigs were removed from pens assigned to treatment 1 to maintain similar initial BW and initial SD while adjusting group size down to 15 pigs per pen.

\section{Animals}

A total of 1,092 crossbred pigs (PIC $359 \times$ Genetiporc F25; PIC, Hendersonville, TN; initial BW of $36.3 \pm 1.2 \mathrm{~kg}$ ) in 56 split-sex pens (barrows and gilts) were used in a 117-d study. Pigs were initially allotted to treatments approximately $10 \mathrm{wk}$ postweaning.

\section{Diets and Housing}

The study was conducted in an insulated, tunnelventilated wean-to-finish barn. Pens contained fully slatted concrete floors and were $5.75 \times 2.50 \mathrm{~m}$ (length $\times$ width). In the case of a pig removal due to illness or death, pen gates were adjusted to maintain the desired floor space allowance. The only changes in floor space that occurred were the changes consistent with the experimental removal strategies. 
Table 2. Diet composition (as-fed basis)

\begin{tabular}{|c|c|c|c|c|}
\hline \multirow[b]{2}{*}{ Item } & \multicolumn{4}{|c|}{ Dietary phase } \\
\hline & 1 & 2 & 3 & 4 \\
\hline $\mathrm{BW}$ range, & 36 to 59 & 59 to 82 & 82 to 100 & 100 to 140 \\
\hline \multicolumn{5}{|l|}{ Ingredient, \% } \\
\hline Corn & 55.22 & 59.62 & 61.54 & 63.39 \\
\hline Soybean meal, $46.5 \% \mathrm{CP}$ & 19.20 & 14.90 & 13.15 & 11.40 \\
\hline $\operatorname{DDGS}^{1}$ & 20.00 & 20.00 & 20.00 & 20.00 \\
\hline $\mathrm{Fat}^{2}$ & 3.50 & 3.50 & 3.43 & 3.35 \\
\hline Calcium carbonate & 0.96 & 0.95 & 0.95 & 0.95 \\
\hline Sodium chloride & 0.44 & 0.44 & 0.44 & 0.44 \\
\hline Lysine sulfate, $46.5 \%$ Lys & 0.44 & 0.37 & 0.36 & 0.34 \\
\hline DL-Methionine & 0.01 & - & - & - \\
\hline Phytase $^{3}$ & 0.023 & 0.018 & 0.013 & 0.005 \\
\hline Copper sulfate & 0.05 & 0.05 & - & - \\
\hline VTM premix ${ }^{4}$ & 0.15 & 0.15 & 0.12 & 0.12 \\
\hline Total & 100.00 & 100.00 & 100.00 & 100.00 \\
\hline \multicolumn{5}{|l|}{ Calculated analysis } \\
\hline \multicolumn{5}{|l|}{ SID AA, ${ }^{5} \%$} \\
\hline Lys & 1.10 & 0.90 & 0.80 & 0.70 \\
\hline TSAA:Lys & 58 & 58 & 58 & 58 \\
\hline Thr:Lys & 62 & 62 & 64 & 68 \\
\hline Trp:Lys & 18 & 18 & 18 & 18 \\
\hline $\mathrm{NE}, \mathrm{Mcal} / \mathrm{kg}$ & 2.61 & 2.64 & 2.65 & 2.66 \\
\hline SID Lys:NE, g/Mcal & 4.21 & 3.41 & 3.02 & 2.63 \\
\hline $\mathrm{Ca}, \%$ & 0.46 & 0.46 & 0.44 & 0.43 \\
\hline $\mathrm{P}, \%$ & 0.40 & 0.40 & 0.38 & 0.37 \\
\hline Available P, \% & 0.28 & 0.27 & 0.25 & 0.21 \\
\hline \multicolumn{5}{|c|}{${ }^{1}$ Dried distillers grains with solubles. } \\
\hline \multicolumn{5}{|c|}{${ }^{2}$ The source of fat was an animal vegetable blend. } \\
\hline \multicolumn{5}{|c|}{$\begin{array}{l}125 \text { phytase units } / \mathrm{kg} \text { of diet, releasing an estimated } 0.11 \%, 0.10 \%, 0.07 \% \text {, } \\
\text { and } 0.04 \% \text { available P for phases } 1,2,3 \text {, and } 4 \text {, respectively. }\end{array}$} \\
\hline \multicolumn{5}{|c|}{${ }^{4} \mathrm{VTM}=$ vitamin and trace mineral premix. The premix provided $14,595 \mathrm{mg}$} \\
\hline \multicolumn{5}{|c|}{$\begin{array}{l}\mathrm{Cu}, 330 \mathrm{ppm} \mathrm{I}, 162,018 \mathrm{mg} \mathrm{Fe}, 44,555 \mathrm{mg} \mathrm{Mn}, 440 \mathrm{mg} \mathrm{Se}, 162,018 \mathrm{mg} \mathrm{Zn} \text {, } \\
\text { and } 573 \mathrm{mg} \mathrm{Co}, 2,943,168 \mathrm{IU} \text { vitamin A, 738,548 IU vitamin D3, 14,698 } \\
\mathrm{IU} \text { vitamin E, } 1,470 \mathrm{mg} \text { vitamin } \mathrm{K}, 2,205 \mathrm{mg} \text { riboflavin, } 18,364 \mathrm{mg} \text { niacin, } \\
11,023 \mathrm{mg} \text { pantothenic acid, and } 14.70 \mathrm{mg} \text { B12 per kg of premix. }\end{array}$} \\
\hline
\end{tabular}

Pigs were given ad libitum access to feed and water throughout the study. Pigs were fed common corn and soybean meal-based diets that contained $20 \%$ dried distillers grains with solubles and $3 \%$ added fat (Table 2). Diets were fed in 4 sequential phases from approximately 36 to 59,59 to 82,82 to 100 , and 100 to $140 \mathrm{~kg}$. Diets were formulated to meet or exceed NRC (2012) recommendations for the nutrient requirements of finishing pigs. The diets were formulated to contain $1.10 \%, 0.90 \%$, $0.80 \%$, and $0.70 \%$ standardized ileal digestible Lys in phases 1 through 4, respectively. Each pen was equipped with a 4-hole (SDI, Alexandria, SD) stainless-steel dry self-feeder with feed pan dimensions of $127 \times 18 \times 15$ cm (length $\times$ width $\times$ height). To help maintain similar linear feeder space across initial floor space allowances, 1 feeder hole in pens stocked at $0.91 \mathrm{~m}^{2}$ (15 pigs/pen; treatment 1 ) was blocked. This provided approximately
6.0 and 5.8 linear $\mathrm{cm}$ of trough space per pig for pens initially stocked at 0.91 and $0.65 \mathrm{~m}^{2}$, respectively. All pens contained 1 pan waterer $(53 \times 20 \mathrm{~cm})$.

\section{Growth Measurements}

All pigs were individually weighed at initiation of the study (d 0) and again on d 64, 76, 95, 105, and 117. Pen weights were also collected on the aforementioned days along with $\mathrm{d} 21$ and 42. Individual weight information was used to identify the heaviest pigs in the pen to market on removal days, to calculate the variation of BW with pens throughout the study, and to evaluate ADG of pigs within pens when categorized into the light, medium, and heavy thirds of the pen. Pen weights along with feed disappearance were used to calculate $\mathrm{ADG}, \mathrm{ADFI}$, and G:F during each period.

\section{Economic Calculations}

Total weight gain per pen was calculated by subtracting the total pen weight on $\mathrm{d} 0$ from the sum of BW from pigs marketed from the pen. The total weight gain per pig was calculated using the total weight gain per pen divided by the number of pigs marketed per pen. Revenue was calculated using a low $(\$ 0.99 / \mathrm{kg})$ and high $(\$ 1.32 \mathrm{~kg})$ base carcass price; then individual $\mathrm{HCW}$ for each pig marketed was calculated using a fixed yield percentage of $75 \%$. To account for premiums and discounts associated with varying individual $\mathrm{HCW}$, the following equation was used: $\$ / \mathrm{Cwt}, \mathrm{kg}=$ $\left(0.0001169532 \times \mathrm{HCW}, \mathrm{kg}^{3}\right)-(0.0516996146 \times \mathrm{HCW}$, $\left.\mathrm{kg}^{2}\right)+(6.6397162094 \times \mathrm{HCW}, \mathrm{kg})-257.58240$, where Cwt is carcass weight. The premium/discount calculation was added to the base price to determine revenue per pig. The individual revenue per pig was summed for the number of pigs in a pen to calculate the revenue per pen. Low $(\$ 220.46 / \mathrm{t})$ and high $(\$ 286.60 / \mathrm{t})$ feed costs were used to calculate feed cost per pen and per pig on the basis of the observed feed intake. Finally, to calculate the income over feed and facility cost (IOFFC) the total feed cost and facility cost (assumed to be $\$ 0.11$ per $0.69 \mathrm{~m}^{2} / \mathrm{d}$ ) were subtracted from the total revenue.

\section{Statistical Analyses}

Pig performance data were analyzed as a generalized randomized block design using the MIXED procedure of SAS (SAS Inst. Inc., Cary, NC) with pen as the experimental unit and sex as the blocking factor. Growth performance within each time period was evaluated using the same statistical model design. Treatment means were analyzed using the LSMEANS statement, and protected pairwise comparisons were performed using the 
Tukey-Kramer multiple-comparison adjustment. A preplanned CONTRAST statement was used to compare the means of pigs initially provided $0.91 \mathrm{~m}^{2}$ of floor space vs. pigs initially provided $0.65 \mathrm{~m}^{2}$ of floor space. Mortality and morbidity were not a normally distributed response; therefore, the GLIMMIX procedure with binomial distribution was used to evaluate treatment means. For BW categorization information, the RANK procedure of SAS was used to rank pigs within the pen into the lightest, medium, and heaviest thirds of the pen prior to each weigh period. The assigned rank was then used as a fixed effect in the model to evaluate the interactive and main effects of experimental treatment and BW category on ADG within each period. Results were considered significant at $P<0.05$ and marginally significant at $P>0.05$ and $P<0.10$.

\section{RESULTS AND DISCUSSION}

\section{Growth Performance}

There were no sex by treatment interactions; therefore, only the main effects of sex and treatment will be discussed. The lack of interaction agrees with results of other researchers (Hugh and Reimer, 1967; Jensen et al., 1973; Hamilton et al., 2003; Peterson, 2004), who have also tested the potential for a sex $\times$ floor space interaction and did not observe a difference in response to floor space allowances between barrows and gilts.

From d 0 to 64, barrows had increased $(P<0.001$; Table 3) ADG and ADFI compared to gilts, but G:F were similar. Barrows and gilts had similar ADG from d 64 to 76; however, barrows had increased $(P<0.001)$ ADFI and poorer $(P<0.001) \mathrm{G}: \mathrm{F}$ during this period. From d 76 to 95 , barrows tended $(P<0.098)$ to have lower ADG and increased $(P=0.068)$ ADFI compared to gilts, which resulted in poorer $(P=0.007) \mathrm{G}: \mathrm{F}$. Barrows had increased $(P=0.018)$ ADFI from d 95 to 105; however, ADG and G:F were similar between sexes. During the final period (d 105 to 117), barrows had lower $(P<$ $0.001)$ ADG and $(P<0.001) \mathrm{G}: \mathrm{F}$ than gilts, but ADFI were not different. Overall (d 0 to 117), barrows had increased $(P<0.002)$ ADG and ADFI and poorer $(P<$ $0.001) \mathrm{G}: \mathrm{F}$ compared to gilts. The differences in performance of gilts and barrows are similar to the differences in lean tissue deposition and maturity curves among sexes discussed by Cline and Richert (2001).

Initial $\mathrm{BW}$ on $\mathrm{d} 0$ was similar across treatments (Table 4). One objective of this study was to use the information to validate whether the ADG and ADFI prediction equations developed by Gonyou et al. (2006) were applicable to heavy-weight finishing pigs. The allometric principle of these equations suggests that as BW increases, the pig's space requirement increases
Table 3. Main effects of sex on the growth of finishing pigs ${ }^{1}$

\begin{tabular}{|c|c|c|c|c|}
\hline \multirow[b]{2}{*}{ Period } & \multicolumn{2}{|c|}{ Sex } & \multirow[b]{2}{*}{ SEM } & \multirow[b]{2}{*}{ Probability $P$} \\
\hline & Barrow & Gilt & & \\
\hline \multicolumn{5}{|l|}{ d 0 to 64} \\
\hline $\mathrm{ADG}, \mathrm{kg}$ & 0.90 & 0.83 & 0.007 & $<0.001$ \\
\hline ADFI, kg & 2.16 & 1.95 & 0.020 & $<0.001$ \\
\hline G:F & 0.419 & 0.425 & 0.003 & $<0.138$ \\
\hline \multicolumn{5}{|l|}{ d 64 to 76} \\
\hline $\mathrm{ADG}, \mathrm{kg}$ & 0.99 & 1.01 & 0.013 & $<0.309$ \\
\hline ADFI, kg & 3.07 & 2.84 & 0.023 & $<0.001$ \\
\hline $\mathrm{G}: \mathrm{F}$ & 0.322 & 0.356 & 0.004 & $<0.001$ \\
\hline \multicolumn{5}{|l|}{ d 76 to 95} \\
\hline $\mathrm{ADG}, \mathrm{kg}$ & 0.94 & 0.98 & 0.019 & $<0.098$ \\
\hline ADFI, kg & 2.99 & 2.93 & 0.026 & $<0.068$ \\
\hline G:F & 0.314 & 0.340 & 0.006 & $<0.007$ \\
\hline \multicolumn{5}{|l|}{ d 95 to 105} \\
\hline $\mathrm{ADG}, \mathrm{kg}$ & 0.85 & 0.86 & 0.032 & $<0.849$ \\
\hline ADFI, kg & 2.99 & 2.88 & 0.033 & $<0.018$ \\
\hline G:F & 0.283 & 0.298 & 0.010 & $<0.294$ \\
\hline \multicolumn{5}{|l|}{ d 105 to 117} \\
\hline ADG, $\mathrm{kg}$ & 0.85 & 0.95 & 0.020 & $<0.001$ \\
\hline ADFI, kg & 3.12 & 3.01 & 0.046 & $<0.103$ \\
\hline G:F & 0.273 & 0.319 & 0.006 & $<0.001$ \\
\hline \multicolumn{5}{|l|}{ d 0 to 117} \\
\hline $\mathrm{ADG}, \mathrm{kg}$ & 0.91 & 0.88 & 0.005 & $<0.002$ \\
\hline ADFI, kg & 2.52 & 2.35 & 0.016 & $<0.001$ \\
\hline $\mathrm{G}: \mathrm{F}$ & 0.360 & 0.375 & 0.002 & $<0.001$ \\
\hline
\end{tabular}

${ }^{1}$ A total of 1,092 pigs (PIC $359 \times$ Genetiporc F25 females; initial BW = $36.3 \mathrm{~kg}$ ) were used in a 117-d study to determine the influence of initial floor space allowance and marketing strategy on growth performance. There were either 15 or 21 pigs per pen and 28 pens per sex. No treatment $\times$ sex interactions were observed for growth performance.

at a rate of $\mathrm{BW}^{0.67}$. This geometric principle was first applied to swine by Petherick and Baxter (1981), who found that as Large White $\times$ Landrace pigs grew, their length and height increased at a rate of BW0.33, thereby increasing the animal's surface area by the proportion of $\mathrm{BW}^{0.67}$. Gonyou et al. (2006) predicted a broken-line requirement for space (on the basis of the allometric measurement of $k=$ floor space, $\left.\mathrm{m}^{2} / \mathrm{BW}, \mathrm{kg} 0.67\right)$, where $k=$ 0.0336 and is the optimal point where maximum ADG and ADFI are achieved, but when space is provided below that value, pigs have reduced ADG and ADFI. The treatments in the current study were designed to test this hypothesis. In treatment 1 , pigs initially stocked at 0.91 $\mathrm{m}^{2}$ should not have been limited on space on the basis of the prediction equations, up to $140 \mathrm{~kg}$. Additionally, for pigs stocked at $0.65 \mathrm{~m}^{2}$, if the 2 heaviest pigs are marketed when average BW reaches 83, 97, and $114 \mathrm{~kg}$ $(2: 2: 2)$, then the pigs remaining in the pen should also achieve maximum ADG and ADFI. Meanwhile, the pigs initially stocked at $0.65 \mathrm{~m}^{2}$ and marketed using more common industry practices of 2 removal points $(2: 4$ removal strategy) or a single removal point (6 removal 
Table 4. The effects of initial floor space and removal strategy on BW of finishing pigs ${ }^{1}$

\begin{tabular}{|c|c|c|c|c|c|c|}
\hline \multirow[b]{4}{*}{ Item } & \multicolumn{4}{|c|}{ Initial floor space, $\mathrm{m}^{2}$} & \multirow[b]{4}{*}{ SEM } & \multirow{4}{*}{$\begin{array}{c}\text { Probability } P \\
\text { initial } \\
\text { floor space }^{3}\end{array}$} \\
\hline & 0.91 & 0.65 & 0.65 & 0.65 & & \\
\hline & \multicolumn{4}{|c|}{ Marketing strategy $^{2}$} & & \\
\hline & None & $2: 2: 2$ & $2: 4$ & 6 & & \\
\hline \multicolumn{7}{|l|}{ Avg BW of pen prior to removals, $\mathrm{kg}$} \\
\hline $\mathrm{d} 0$ & 36.4 & 36.3 & 36.3 & 36.3 & 0.32 & $<0.835$ \\
\hline d 64 & $93.7^{\mathrm{a}}$ & $92.0^{\mathrm{a}, \mathrm{b}}$ & $91.3^{\mathrm{b}}$ & $91.6^{\mathrm{a}, \mathrm{b}}$ & 0.62 & $<0.007$ \\
\hline d 76 & $105.6^{\mathrm{a}}$ & $102.9^{\mathrm{b}}$ & $102.8^{\mathrm{b}}$ & $103.4^{\mathrm{a}, \mathrm{b}}$ & 0.68 & $<0.002$ \\
\hline d 95 & $125.5^{\mathrm{a}}$ & $119.9^{\mathrm{b}}$ & $118.7^{\mathrm{b}}$ & $121.3^{\mathrm{b}}$ & 0.79 & $<0.001$ \\
\hline d 105 & $134.1^{\mathrm{a}}$ & $127.5^{\mathrm{b}}$ & $127.8^{\mathrm{b}}$ & $129.0^{\mathrm{b}}$ & 0.80 & $<0.001$ \\
\hline d 117 & $144.8^{\mathrm{a}}$ & $138.4^{\mathrm{b}}$ & $135.5^{\mathrm{b}}$ & $135.0^{\mathrm{b}}$ & 1.00 & $<0.001$ \\
\hline \multicolumn{7}{|l|}{ Avg BW of pigs removed, $\mathrm{kg}$} \\
\hline d 0 & - & - & - & - & - & - \\
\hline d 64 & - & 107.1 & - & - & - & - \\
\hline d 76 & - & 115.0 & 120.2 & - & 0.79 & - \\
\hline d 95 & - & 131.0 & - & - & - & - \\
\hline d 105 & - & - & 139.9 & 140.4 & 0.81 & - \\
\hline d 117 & $144.8^{\mathrm{a}}$ & $138.4^{\mathrm{b}}$ & $135.5^{\mathrm{b}}$ & $135.0^{\mathrm{b}}$ & 1.00 & $<0.001$ \\
\hline \multicolumn{7}{|c|}{ Avg BW of pigs remaining in pen after removals, $\mathrm{kg}$} \\
\hline $\mathrm{d} 0$ & - & - & - & - & - & - \\
\hline d 64 & - & 90.3 & - & - & - & - \\
\hline d 76 & - & 100.9 & 101.4 & - & 0.63 & - \\
\hline d 95 & - & 118.3 & - & - & - & - \\
\hline d 105 & - & - & 124.4 & 124.1 & 0.89 & - \\
\hline d 117 & - & - & - & - & - & - \\
\hline Avg BW of pigs at time of removal, $\mathrm{kg}$ & $144.8^{\mathrm{a}}$ & $132.3^{\mathrm{c}}$ & $134.9^{\mathrm{b}, \mathrm{c}}$ & $136.6^{\mathrm{b}}$ & 0.87 & $<0.001$ \\
\hline
\end{tabular}

${ }^{\mathrm{a}-\mathrm{c}}$ Means without a common superscript letter $\operatorname{differ}(P<0.05)$.

${ }^{1}$ A total of 1,092 pigs (PIC $359 \times$ Genetiporc F25 females; initial BW $=36.3 \mathrm{~kg}$ ) were used in a 117-d study to determine the influence of initial floor space allowance and removal strategy on growth performance. There were either 15 or 21 pigs per pen and 14 pens ( 7 barrow and 7 gilt pens) per treatment at the start of the trial.

${ }^{2}$ Pigs initially provided $0.65 \mathrm{~m}^{2}$ of floor space were removed using 3 different strategies: 2:2:2 signifies pens where the 2 heaviest pigs on $\mathrm{d} 64,76$, and 95 were removed; 2:4 represents pens where the heaviest 2 pigs were removed on d 76 and the 4 heaviest pigs were removed on d 105; and 6 represents pens where the heaviest 6 pigs were removed on $\mathrm{d} 105$.

${ }^{3}$ Initial floor space compares the mean of pigs initially provided 0.91 or $0.65 \mathrm{~m}^{2}$.

strategy) will still have limited ADG and ADFI until the final marketing event occurs. Then for the final period (d 105 to 117), after all removal events have taken place, pigs remaining in pens initially provided $0.65 \mathrm{~m}^{2}(2: 2: 2$, $2: 4,6)$ should have enough space for ADG and ADFI to be similar to pigs initially stocked at $0.91 \mathrm{~m}^{2}$.

From d 0 to 64, pigs initially provided $0.91 \mathrm{~m}^{2}$ of floor space had greater $(P<0.003$; Table 5) ADG and ADFI compared to pigs initially provided $0.65 \mathrm{~m}^{2}$ of floor space, regardless of removal strategy, but G:F was not different between treatments. On d 64, the mean BW of pigs provided $0.91 \mathrm{~m}^{2}$ of floor space was heavier $(P=0.007)$ than that of pigs initially provided $0.65 \mathrm{~m}^{2}$ of floor space and on the $2: 4$ removal strategy.

The objective was to remove the first 2 heaviest pigs from pens on the 2:2:2 removal strategy when BW reached $83 \mathrm{~kg}$. However, pigs were not removed until d 64 when average BW was $92 \mathrm{~kg}$; therefore, a depression in ADG and ADFI was expected for pigs from 83 to 92 $\mathrm{kg}$, and that is illustrated by the calculated $k$ coefficients listed in Table 6 . The predicted reduction by Gonyou et al. (2006) in ADG and ADFI for this period was 1.4\% and $4.9 \%$, respectively. However, the observed reduction in ADG and ADFI between treatment pigs provided 0.91 and $0.65 \mathrm{~m}^{2}$ was $3.4 \%$ and $5.1 \%$, respectively. This suggests that the predicted outcomes were underestimated for ADG. Potter et al. (2010) reported similar findings when finishing pigs were stocked at 22, 24, 26, or 28 pigs per pen. However, the authors attributed the larger than predicted reduction in $\mathrm{ADG}$ to be from reduced trough space, which was confounded by the different group sizes. However, Thomas et al. (2015) concluded the same findings when evaluating floor space allowance effects on finishing pigs. The researchers controlled feeder space by adjusting gates to achieve floor space treatments, rather than group size. In both the aforementioned studies, reductions occurred prior to pigs reaching the calculated BW needed to reduce the coefficient $k$ below the critical threshold expected to reduce ADG. That would suggest the breakpoint estimated 
Table 5. The effects of initial floor space and removal strategy on the growth of finishing pigs ${ }^{1}$

\begin{tabular}{|c|c|c|c|c|c|c|}
\hline \multirow[b]{4}{*}{ Item } & \multicolumn{4}{|c|}{ Initial floor space, $\mathrm{m}^{2}$} & \multirow[b]{4}{*}{ SEM } & \multirow{4}{*}{$\begin{array}{c}\text { Probability } P \\
\text { Initial } \\
\text { floor space }\end{array}$} \\
\hline & 0.91 & 0.65 & 0.65 & 0.65 & & \\
\hline & \multicolumn{4}{|c|}{ Marketing strategy $^{2}$} & & \\
\hline & None & $2: 2: 2$ & $2: 4$ & 6 & & \\
\hline \multicolumn{7}{|l|}{$\mathrm{d} 0$ to 64} \\
\hline Pigs per pen, $n$ & 15 & 21 & 21 & 21 & & \\
\hline $\mathrm{ADG}, \mathrm{kg}$ & $0.89^{\mathrm{a}}$ & $0.86^{\mathrm{a}, \mathrm{b}}$ & $0.85^{\mathrm{b}}$ & $0.85^{\mathrm{b}}$ & 0.010 & $<0.003$ \\
\hline ADFI, $\mathrm{kg}$ & $2.14^{\mathrm{a}}$ & $2.03^{\mathrm{b}}$ & $2.02^{\mathrm{b}}$ & $2.03^{b}$ & 0.028 & $<0.001$ \\
\hline $\mathrm{G}: \mathrm{F}$ & 0.418 & 0.426 & 0.424 & 0.419 & 0.004 & $<0.178$ \\
\hline \multicolumn{7}{|l|}{ d 64 to 76} \\
\hline Pigs per pen, $n$ & 15 & 19 & 21 & 21 & & \\
\hline $\mathrm{ADG}, \mathrm{kg}$ & $1.03^{\mathrm{a}}$ & $1.04^{\mathrm{a}}$ & $0.94^{\mathrm{b}}$ & $0.98^{\mathrm{a}, \mathrm{b}}$ & 0.019 & $<0.040$ \\
\hline ADFI, $\mathrm{kg}$ & $3.10^{\mathrm{a}}$ & $2.96^{\mathrm{b}}$ & $2.84^{\mathrm{c}}$ & $2.91^{\mathrm{b}, \mathrm{c}}$ & 0.032 & $<0.001$ \\
\hline $\mathrm{G}: \mathrm{F}$ & $0.334^{\mathrm{a}, \mathrm{b}}$ & $0.352^{\mathrm{b}}$ & $0.332^{\mathrm{a}}$ & $0.337^{\mathrm{a}, \mathrm{b}}$ & 0.005 & $<0.310$ \\
\hline \multicolumn{7}{|l|}{ d 76 to 95} \\
\hline Pigs per pen, $n$ & 15 & 17 & 19 & 21 & & \\
\hline $\mathrm{ADG}, \mathrm{kg}$ & $1.03^{\mathrm{a}}$ & $0.97^{\mathrm{a}, \mathrm{b}}$ & $0.93^{\mathrm{b}}$ & $0.92^{\mathrm{b}}$ & 0.027 & $<0.005$ \\
\hline ADFI, $\mathrm{kg}$ & $3.16^{\mathrm{a}}$ & $2.94^{\mathrm{b}}$ & $2.87^{\mathrm{b}}$ & $2.88^{\mathrm{b}}$ & 0.037 & $<0.001$ \\
\hline $\mathrm{G}: \mathrm{F}$ & 0.326 & 0.332 & 0.323 & 0.320 & 0.008 & $<0.938$ \\
\hline \multicolumn{7}{|l|}{ d 95 to 105} \\
\hline Pigs per pen, $n$ & 15 & 15 & 19 & 21 & & \\
\hline $\mathrm{ADG}, \mathrm{kg}$ & 0.86 & 0.92 & 0.89 & 0.75 & 0.046 & 0.890 \\
\hline ADFI, $\mathrm{kg}$ & $3.03^{\mathrm{a}}$ & $3.02^{\mathrm{a}}$ & $2.93^{\mathrm{a}, \mathrm{b}}$ & $2.76^{\mathrm{b}}$ & 0.046 & 0.024 \\
\hline $\mathrm{G}: \mathrm{F}$ & 0.283 & 0.305 & 0.305 & 0.270 & 0.014 & 0.545 \\
\hline \multicolumn{7}{|l|}{ d 105 to 117} \\
\hline Pigs per pen, $n$ & 15 & 15 & 15 & 15 & & \\
\hline $\mathrm{ADG}, \mathrm{kg}$ & 0.88 & 0.90 & 0.92 & 0.91 & 0.028 & $<0.340$ \\
\hline ADFI, kg & 3.20 & 3.04 & 3.03 & 2.98 & 0.066 & $<0.022$ \\
\hline $\mathrm{G}: \mathrm{F}$ & 0.275 & 0.299 & 0.305 & 0.304 & 0.008 & $<0.005$ \\
\hline \multicolumn{7}{|l|}{ d 0 to 117} \\
\hline $\mathrm{ADG}, \mathrm{kg}$ & $0.92^{\mathrm{a}}$ & $0.90^{\mathrm{a}, \mathrm{b}}$ & $0.88^{b, c}$ & $0.87^{\mathrm{c}}$ & 0.008 & $<0.001$ \\
\hline ADFI, kg & $2.58^{\mathrm{a}}$ & $2.40^{\mathrm{b}}$ & $2.39^{\mathrm{b}}$ & $2.39^{\mathrm{b}}$ & 0.022 & $<0.001$ \\
\hline $\mathrm{G}: \mathrm{F}$ & $0.358^{\mathrm{c}}$ & $0.377^{\mathrm{a}}$ & $0.370^{\mathrm{a}, \mathrm{b}}$ & $0.364^{\mathrm{b}, \mathrm{c}}$ & 0.002 & $<0.001$ \\
\hline
\end{tabular}

${ }^{\mathrm{a}-\mathrm{c}}$ Means without a common superscript letter $\operatorname{differ}(P<0.05)$.

${ }^{1} \mathrm{~A}$ total of 1,092 pigs (PIC $359 \times$ Genetiporc F25 females; initial BW $=36.3 \mathrm{~kg}$ ) were used in a 117-d study to determine the influence of initial floor space allowance and removal strategy on growth performance. There were either 15 or 21 pigs per pen and 14 pens ( 7 barrow and 7 gilt pens) per treatment at the start of the trial.

${ }^{2}$ Pigs initially provided $0.65 \mathrm{~m}^{2}$ of floor space were removed using 3 different strategies: 2:2:2 signifies pens where the 2 heaviest pigs on d 64, 76, and 95 were removed; $2: 4$ represents pens where the heaviest 2 pigs were removed on $\mathrm{d} 76$ and the 4 heaviest pigs were removed on d 105 ; and 6 represents pens where the heaviest 6 pigs were removed on d 105.

${ }^{3}$ Initial floor space compares the mean of pigs initially provided 0.91 or $0.65 \mathrm{~m}^{2}$.

by Gonyou et al. (2006) needed for maximal ADG is underestimated at $k=0.0336$. The results reported from d 0 to 64 herein support the same conclusion; however, since the heaviest pigs on the 2:2:2 marketing strategy were removed and marketed after the time point when average BW was $83 \mathrm{~kg}$ (needed to keep $k \geq 0.0336$ ), it is unclear whether the higher than expected reduction in ADG is due to the critical threshold of 0.0336 underestimating the true threshold of the pig's space requirement or if the slope associated with the linear reduction in ADG, below the critical point, is underestimating the reduction in $\mathrm{ADG}$ when pigs were limited on floor space.

From d 64 to 76, pigs on the 2:4 removal strategy had decreased $(P<0.006)$ ADG compared to pigs initially provided $0.91 \mathrm{~m}^{2}$ of floor space and pigs initially provided $0.65 \mathrm{~m}^{2}$ of floor space on the 2:2:2 removal strategy. This was expected since pigs on the $2: 4$ and 6 removal strategies were still stocked at $0.65 \mathrm{~m}^{2}$, which was below their predicted space requirement. Additionally, ADFI was higher $(P<0.019)$ for pigs initially provided $0.91 \mathrm{~m}^{2}$ of floor space compared to pigs initially provided $0.65 \mathrm{~m}^{2}$ of floor space regardless of removal strategy. Pigs remaining in pens on the 2:2:2 removal strategy had increased $(P=0.049)$ ADFI compared to pigs on the $2: 4$ removal strategy. Feed efficiency was also increased $(P=0.035)$ for pigs on the 2:2:2 removal strategy compared to pigs on the 2:4 removal strategy. On $\mathrm{d} 76$, mean BW of pigs provided $0.91 \mathrm{~m}^{2}$ of floor space was heavier $(P<0.033)$ 
Table 6. Calculated $k$ coefficients based on floor space and removal strategy 1

\begin{tabular}{|c|c|c|c|c|}
\hline \multirow{4}{*}{$\begin{array}{l}\text { Calculated } \\
\text { k coefficient }{ }^{2}\end{array}$} & \multicolumn{4}{|c|}{ Initial floor space, $\mathrm{m}^{2}$} \\
\hline & 0.91 & 0.65 & 0.65 & 0.65 \\
\hline & \multicolumn{4}{|c|}{ Marketing strategy ${ }^{3}$} \\
\hline & None & $2: 2: 2$ & $2: 4$ & 6 \\
\hline $\mathrm{d} 0$ & $0.0819(0.91)$ & $0.0586(0.65)$ & $0.0586(0.65)$ & $0.0586(0.65)$ \\
\hline \multicolumn{5}{|l|}{ d 64} \\
\hline Prior to removals & $0.0434(0.91)$ & $0.0314(0.65)$ & $0.0316(0.65)$ & $0.0315(0.65)$ \\
\hline After removals & - & $0.0352(0.72)$ & - & - \\
\hline \multicolumn{5}{|l|}{ d 76} \\
\hline Prior to removals & $0.0401(0.91)$ & $0.0323(0.72)$ & $0.0292(0.65)$ & $0.0291(0.65)$ \\
\hline After removals & - & $0.0363(0.80)$ & $0.0326(0.72)$ & - \\
\hline \multicolumn{5}{|l|}{ d 95} \\
\hline Prior to removals & $0.0357(0.91)$ & $0.0324(0.80)$ & $0.0293(0.72)$ & $0.0261(0.65)$ \\
\hline After removals & - & $0.0372(0.91)$ & - & - \\
\hline \multicolumn{5}{|l|}{ d 105} \\
\hline Prior to removals & $0.0342(0.91)$ & $0.0353(0.91)$ & $0.0279(0.72)$ & $0.0251(0.65)$ \\
\hline After removals & - & - & $0.0359(0.91)$ & $0.0360(0.91)$ \\
\hline d 117 & $0.0325(0.91)$ & $0.0335(0.91)$ & $0.0339(0.91)$ & $0.0340(0.91)$ \\
\hline
\end{tabular}

${ }^{1}$ A total of 1,092 pigs (PIC $359 \times$ Genetiporc F25 females; initial BW $=36.3 \mathrm{~kg}$ ) were used in a 117 -d study to determine the influence of initial floor space allowance and removal strategy on growth performance. There were either 15 or 21 pigs per pen and 14 pens ( 7 barrow and 7 gilt pens) per treatment at the start of the trial.

${ }^{2}$ The constant coefficient $k$ is calculated as $k=$ floor space, $\mathrm{m}^{2} / \mathrm{BW}^{0.67}$. Coefficients in bold represent values below the predicted critical threshold of $k=$ 0.0336 predicted by Gonyou et al. (2006) as the required amount of space needed to maximize ADG and ADFI.

${ }^{3}$ Pigs initially provided $0.65 \mathrm{~m}^{2}$ of floor space were removed using 3 different strategies: 2:2:2 signifies pens where the 2 heaviest pigs on $\mathrm{d} 64,76$, and 95 were removed; 2:4 represents pens where the heaviest 2 pigs were removed on $\mathrm{d} 76$ and the 4 heaviest pigs were removed on d 105 ; and 6 represents pens where the heaviest 6 pigs were removed on $\mathrm{d} 105$. Values in parentheses represent the floor space allowance $\left(\mathrm{m}^{2}\right)$ pigs remaining in pens were provided based on initial floor space and marketing strategy.

than that of pigs on the 2:2:2 and 2:4 removal strategies. The fact that pigs remaining in pens on the 2:2:2 removal strategy had similar ADG during this period as pigs provided $0.91 \mathrm{~m}^{2}$ of floor space suggests that relieving stocking pressure and providing additional floor space resulted in improvements in gain. Interestingly, by the end of the period their calculated $k$ coefficient $(0.0323)$ was still below their predicted need, but it did not seem to affect their gain. Also, ADFI of pigs remaining in pens on the 2:2:2 removal strategy was improved compared that of pigs on the 2:4 removal strategy, suggesting that providing additional floor space to the pigs remaining in the pen changed their feeding behavior. This has previously been reported by Augspurger et al. (2000), who found that removing pigs from pens caused changes in feeding behavior to be more like that of pigs in intact pens of the same group size. But in the current study, pigs remaining in pens on the 2:2:2 removal strategy did not consume as much as pigs initially provided $0.91 \mathrm{~m}^{2}$ of floor space. This may be because the heaviest pigs were removed from the pen on $\mathrm{d} 64$, which reduced the voluntary feed intake of the pigs remaining below that of pigs in intact pens provided $0.91 \mathrm{~m}^{2}$ of floor space.

From d 76 to 95 , pigs initially provided $0.91 \mathrm{~m}^{2}$ of floor space had increased $(P<0.046)$ ADG compared to pigs on the 2:4 and 6 removal strategies. Additionally, pigs provided $0.91 \mathrm{~m}^{2}$ of floor space had increased
$(P<0.001)$ ADFI compared to pigs initially provided $0.65 \mathrm{~m}^{2}$ regardless of the removal strategy. Feed efficiency was similar regardless of treatment. During this period, it was expected that pigs remaining in pens on the 2:4 removal strategy would have improved ADG and ADFI compared to pigs on the 6 removal strategy, but that was not observed. Although they were still below their predicted space requirement to reach maximal $\mathrm{ADG}$ and $\mathrm{ADFI}$, these pigs performed similarly to those on the 6 removal strategy who had less space ( $k$ coefficient 0.0326 vs. 0.0291 for pigs on the $2: 4$ and 6 removal strategies, respectively). On d 95, pigs provided $0.91 \mathrm{~m}^{2}$ had heavier $(P<0.002)$ mean BW compared to pigs initially provided $0.65 \mathrm{~m}^{2}$, regardless of removal strategy.

From $\mathrm{d} 95$ to 105 , pigs remaining in pens on the 2:2:2 removal strategy had marginally significantly increased ADG $(P=0.054)$ compared to pigs on the 6 removal strategy. Average daily feed intake was greater $(P<0.001)$ for pigs initially provided $0.91 \mathrm{~m}^{2}$ or on the 2:2:2 removal strategy compared to pigs on the 6 removal strategy. Feed efficiency was similar regardless of experimental treatment. The importance of space for late finishing pigs was most evident during this period where pigs on the 6 removal strategy, who were still stocked at $0.65 \mathrm{~m}^{2}$ and had greatly decreased ADG and ADFI compared to the other treatments. On d 105 , average $\mathrm{BW}$ of pigs provided $0.91 \mathrm{~m}^{2}$ of floor 
space was heavier $(P<0.001)$ than that of pigs initially provided $0.65 \mathrm{~m}^{2}$, regardless of removal strategy.

During the final period from d 105 to 117, after all removal strategies were completed, ADG and ADFI were similar regardless of treatment. This suggests that removing pigs and providing additional floor space was useful in recapturing ADG and ADFI back to levels similar to that of pigs maintained with adequate floor space. Feed efficiency was marginally significantly $(P<0.070)$ higher for pigs remaining in pens on the 2:4 and 6 removal strategies compared to pigs initially provided $0.91 \mathrm{~m}^{2}$ of floor space. That is not surprising considering that the mean $\mathrm{BW}$ of pigs provided $0.91 \mathrm{~m}^{2}$ of floor space was heavier $(P<$ $0.001)$ on $d 117$ than that of pigs initially provided $0.65 \mathrm{~m}^{2}$ of floor space, regardless of removal strategy.

Over the entire length of the study, from d 0 to 117 , pigs provided $0.91 \mathrm{~m}^{2}$ of floor space had greater $(P<$ $0.002)$ ADG compared to pigs on the $2: 4$ and 6 removal strategies. Also, pigs on the 2:2:2 removal strategy had increased $(P=0.018)$ ADG compared to pigs on the 6 removal strategy. Pigs provided $0.91 \mathrm{~m}^{2}$ had greater $(P<0.001)$ ADFI compared to pigs initially provided $0.65 \mathrm{~m}^{2}$, regardless of removal strategy. Pigs on the 2:2:2 removal strategy had improved $(P<0.001) \mathrm{G}: \mathrm{F}$ compared to pigs initially provided $0.91 \mathrm{~m}^{2}$ of floor space or pigs on the 6 removal strategy. Additionally, pigs on the 2:4 removal strategy had improved $(P=$ 0.029) G:F compared to pigs initially provided $0.91 \mathrm{~m}^{2}$ of floor space. Pigs initially provided $0.91 \mathrm{~m}^{2}$ of floor space had heavier $(P<0.001)$ average $\mathrm{BW}$ at removal compared to pigs initially provided $0.65 \mathrm{~m}^{2}$, regardless of removal strategy. Also, pigs on the 2:2:2 removal strategy had lighter $(P<0.005)$ average BW at removal compared to pigs on the 6 removal strategy.

Growth performance results from the current study agree with previous research examining the impact of removals on finishing pig growth performance (Woodworth et al., 2000; DeDecker et al., 2005; Jacela et al., 2009) in the sense that removing heavy-weight pen mates from a pen results in the remaining pigs having increased ADG and ADFI compared to pigs in intact pens. Interestingly, Bates and Newcomb (1997) and Woodworth et al. (2000) observed no impact of pig removal on the $\mathrm{G}: \mathrm{F}$ of those animals remaining. Alternatively, DeDecker et al. (2005) observed an improvement in feed efficiency for pigs remaining in pens after the removals were conducted. Also, Jacela et al. (2009) observed improved feed efficiency for pigs remaining in pens after removals occurred compared to intact pens. Chapple (1993) hypothesized that the improvements in performance of pigs in smaller group sizes may be due to biological and hormonal changes that increase protein deposition and correspondingly feed efficiency compared to commercially reared pigs in larger group environments. However, in the case of most removal studies, the heaviest pigs are the animals removed, suggesting that the difference in BW of the pigs remaining in the pen after removals occur may be the driver of the differences in feed efficiency that are observed. In the present study, overall G:F was poorer for pens initially provided $0.91 \mathrm{~m}^{2}$ of floor space compared to pens on the 2:2:2 removal strategy. This difference could be attributed to the lower average BW of the pigs remaining in pens on the 2:2:2 removal strategy after removals occurred. If the feed efficiency values are adjusted to account for differences in final BW using the G:F adjustments proposed by Gonçalves et al. (2016), then there is a marginally significant $(P=$ 0.072 ) improvement in G:F for pigs on the $2: 2: 2$ removal strategy (treatment mean of 0.364 ) compared to pigs on the 6 marketing strategy (treatment mean of 0.356 ), but no other significant differences are observed, with treatment means of 0.357 and 0.360 for pigs initially provided $0.91 \mathrm{~m}^{2}$ of space and pigs on the 2:4 removal strategy, respectively.

The specific source of the improvements in ADG and ADFI following pig removals is still debatable. It has been said that the additional resources that become present after pig removals may be the leading factor. The most notable resources that increase are floor space, feeder space, and water space. On the basis of previous research, floor space appears to be the most definite factor that affects growth rate (Moser et al., 1985; Hamilton et al., 2003; Potter et al., 2010). However, some studies have confounded the effects of floor space and feeder space because they alter group size to achieve the desired floor space treatments rather than pen size, and the feeder or trough space is not controlled with the varying number of pigs within a pen. Therefore, it makes it harder to interpret the results and attribute the response to a single source. However, the current study reduced feeder space for pigs initially provided $0.91 \mathrm{~m}^{2}$ of floor space to more closely mimic the trough space in pens initially provided $0.65 \mathrm{~m}^{2}$. The available trough space in the current trial was between 5.8 and $6.0 \mathrm{~cm} / \mathrm{pig}$, which was higher than in previous research by Myers et al. (2012) that found trough space of $4.45 \mathrm{~cm} / \mathrm{pig}$ was adequate for maximum growth; therefore, the trough space in the current study should have been enough to mitigate a trough space effect on the growth performance of the pigs across initial floor space treatments. Research examining the effects of water space (pigs per waterer) on growth is limited. In the current study, water space was not adjusted, but water pans were used that may have allowed more than 1 pig access to water at a time.

The available resources for the pigs within the study and the previous literature suggest that the increased floor 
Table 7. The effects of initial floor space allowance and removal strategy on the within-pen BW variation of finishing pigs ${ }^{1}$

\begin{tabular}{|c|c|c|c|c|c|c|}
\hline \multirow[b]{4}{*}{ Item } & \multicolumn{4}{|c|}{ Initial floor space, $\mathrm{m}^{2}$} & \multirow[b]{4}{*}{ SEM } & \multirow{4}{*}{$\begin{array}{c}\text { Probability } P, \\
\text { initial } \\
\text { floor space }^{3}\end{array}$} \\
\hline & 0.91 & 0.65 & 0.65 & 0.65 & & \\
\hline & \multicolumn{4}{|c|}{ Marketing strategy $^{2}$} & & \\
\hline & None & $2: 2: 2$ & $2: 4$ & 6 & & \\
\hline \multicolumn{7}{|l|}{ CV of within-pen BW } \\
\hline $\mathrm{d} 0$ & 15.5 & 14.8 & 15.2 & 14.1 & 0.67 & $<0.295$ \\
\hline \multicolumn{7}{|l|}{ d 64} \\
\hline Prior to removals & 12.6 & 11.1 & 11.6 & 11.8 & 0.56 & $<0.107$ \\
\hline After removals & $12.6^{\mathrm{b}}$ & $10.0^{\mathrm{a}}$ & $11.6^{\mathrm{a}, \mathrm{b}}$ & $11.8^{\mathrm{a}, \mathrm{b}}$ & 0.57 & $<0.041$ \\
\hline \multicolumn{7}{|l|}{ d 76} \\
\hline Prior to removals & $11.5^{\mathrm{b}}$ & $9.1^{\mathrm{a}}$ & $10.8^{\mathrm{a}, \mathrm{b}}$ & $11.1^{\mathrm{a}, \mathrm{b}}$ & 0.56 & $<0.067$ \\
\hline After removals & $11.5^{\mathrm{b}}$ & $8.5^{\mathrm{a}}$ & $9.7^{\mathrm{a}, \mathrm{b}}$ & $11.1^{\mathrm{b}}$ & 0.67 & $<0.012$ \\
\hline \multicolumn{7}{|l|}{ d 95} \\
\hline Prior to removals & $9.8^{b}$ & $7.7^{\mathrm{a}}$ & $9.0^{\mathrm{a}, \mathrm{b}}$ & $9.3^{\mathrm{b}}$ & 0.42 & $<0.022$ \\
\hline After removals & $9.8^{b}$ & $7.1^{\mathrm{a}}$ & $9.0^{\mathrm{b}}$ & $9.3^{\mathrm{b}}$ & 0.43 & $<0.007$ \\
\hline \multicolumn{7}{|l|}{ d 105} \\
\hline Prior to removals & $9.3^{b}$ & $6.9^{\mathrm{a}}$ & $8.2^{\mathrm{a}, \mathrm{b}}$ & $8.7^{\mathrm{b}}$ & 0.40 & $<0.004$ \\
\hline After removals & $9.3^{b}$ & $6.9^{\mathrm{a}}$ & $6.7^{\mathrm{a}}$ & $7.0^{\mathrm{a}}$ & 0.50 & $<0.001$ \\
\hline d 117 & $9.0^{\mathrm{b}}$ & $6.5^{\mathrm{a}}$ & $6.5^{\mathrm{a}}$ & $6.8^{\mathrm{a}}$ & 0.40 & $<0.001$ \\
\hline Morbidity and mortality, ${ }^{4} \%$ & 2.86 & 2.89 & 3.61 & 5.40 & 1.324 & $<0.503$ \\
\hline
\end{tabular}

${ }^{\mathrm{a}, \mathrm{b}}$ Means without a common superscript letter differ $(P<0.05)$.

${ }^{1}$ A total of 1,092 pigs (PIC $359 \times$ Genetiporc F25 females; initial BW $=36.3 \mathrm{~kg}$ ) were used in a 117-d study to determine the influence of initial floor space allowance and removal strategy on growth performance. There were either 15 or 21 pigs per pen and 14 pens ( 7 barrow and 7 gilt pens) per treatment.

${ }^{2}$ Pigs initially provided $0.65 \mathrm{~m}^{2}$ of floor space were removed using 3 different strategies: 2:2:2 signifies pens where the 2 heaviest pigs on $\mathrm{d} 64,76$, and 95 were removed; 2:4 represents pens where the heaviest 2 pigs were removed on d 76 and the 4 heaviest pigs were removed on d 105; and 6 represents pens where the heaviest 6 pigs were removed on $\mathrm{d} 105$.

${ }^{3}$ Initial floor space compares the mean of pigs initially provided 0.91 or $0.65 \mathrm{~m}^{2}$.

${ }^{4}$ Morbidity and mortality were analyzed as a binomial distribution and were based on the actual number of pigs marketed divided by initial pen inventories.

space for pigs remaining after removals is the most important source of the improved growth rates. Additionally, Scroggs et al. (2002) measured physiological and behavioral responses among pigs in pens that remained intact compared to pigs in pens after removals occurred and found no detectable differences among responses. This result suggests that physiological and biological differences did not result from the removal process, which also strengthens the argument that floor space is the dominant contributor to growth improvements.

On the basis of the current study and the growth data from $\mathrm{d} 0$ to 64, it appeared that prediction equations for ADG and ADFI developed by Gonyou et al. (2006) for varying group sizes of finishing pigs on slatted floors slightly underestimated either the threshold of $k$ needed to achieve maximum ADG and ADFI or the slope of the linear reduction in ADG and ADFI when the animal is below its critical space threshold. This result would support the conclusions of Potter et al. (2010) and Thomas et al. (2015), who observed reductions in ADG and ADFI prior to $k=0.0336$. However, because the performance of pigs initially provided $0.91 \mathrm{~m}^{2}$ and those pigs on the 2:2:2 removal strategy were similar over the entire study (d 0 to 117) and because growth was similar from d 105 to 117 across all treatments, it appears that the concept of an allometric requirement is valid and useful as a predictor of floor space needs of heavier-BW pigs.

\section{Within-Pen BW Variation}

On $\mathrm{d} 0$, the within-pen BW variation was similar (Table 7) across treatments. On d 64, prior to removing the heaviest 2 pigs from treatment 2, within-pen BW variation was similar across treatments, but after the removals occurred, the within-pen $\mathrm{BW}$ variation of pigs remaining in pens on the 2:2:2 removal strategy was less $(P=0.029)$ than that of pigs in pens initially provided $0.91 \mathrm{~m}^{2}$ of floor space. On $\mathrm{d} 76$, prior to removing the 2 heaviest pigs from pens on the 2:2:2 and the $2: 4$ removal strategies, within-pen $\mathrm{BW}$ variation was less $(P=$ 0.030 ) for pens on the $2: 2: 2$ removal strategy compared to pens initially providing $0.91 \mathrm{~m}^{2}$ of floor space. After the removals occurred, BW CV numerically decreased for pigs remaining in pens on the 2:2:2 and 2:4 removal strategies, but only the 2:2:2 removal strategy $\mathrm{CV}$ was significantly less $(P=0.004)$ than that of pigs in pens initially provided $0.91 \mathrm{~m}^{2}$ of floor space. On $\mathrm{d} 95$ prior to removals, the 2:2:2 removal strategy pigs had less $(P<$ 
Table 8. The effects of initial floor space and removal strategy on ADG of BW groups (light, medium, or heavy pigs within pens) $)^{1}$

\begin{tabular}{|c|c|c|c|c|c|c|c|}
\hline Initial floor space, $\mathrm{m}^{2}$ & Marketing strategy $^{2}$ & BW group ${ }^{3}$ & d 0 to 64 & d 64 to 76 & d 76 to 95 & d 95 to 105 & d 105 to 117 \\
\hline 0.91 & None & Light & 0.82 & 0.98 & 1.00 & 0.88 & 0.81 \\
\hline 0.91 & None & Medium & 0.88 & 1.03 & 0.98 & 0.93 & 0.94 \\
\hline 0.91 & None & Heavy & 0.97 & 1.02 & 1.02 & 0.87 & 0.87 \\
\hline 0.91, no. of pigs per pen & & & 15 & 15 & 15 & 15 & 15 \\
\hline 0.65 & $2: 2: 2$ & Light & 0.81 & 1.03 & 0.98 & 0.90 & 0.92 \\
\hline 0.65 & $2: 2: 2$ & Medium & 0.87 & 1.02 & 1.00 & 0.93 & 0.93 \\
\hline 0.65 & $2: 2: 2$ & Heavy & 0.91 & 1.06 & 0.99 & 0.95 & 0.90 \\
\hline 0.65, no. of pigs per pen & & & 21 & 19 & 17 & 15 & 15 \\
\hline 0.65 & $2: 4$ & Light & 0.82 & 0.89 & 0.88 & 0.84 & 0.92 \\
\hline 0.65 & $2: 4$ & Medium & 0.84 & 0.94 & 0.94 & 0.86 & 0.94 \\
\hline 0.65 & $2: 4$ & Heavy & 0.91 & 0.97 & 0.96 & 0.87 & 0.94 \\
\hline 0.65, no. of pigs per pen & & & 21 & 21 & 19 & 19 & 15 \\
\hline 0.65 & 6 & Light & 0.80 & 0.91 & 0.93 & 0.76 & 0.94 \\
\hline 0.65 & 6 & Medium & 0.86 & 0.96 & 0.95 & 0.74 & 0.94 \\
\hline 0.65 & 6 & Heavy & 0.92 & 0.98 & 0.92 & 0.75 & 0.84 \\
\hline 0.65, no. of pigs per pen & & & 21 & 21 & 21 & 21 & 15 \\
\hline SEM & & & 0.04 & 0.027 & 0.045 & 0.057 & 0.085 \\
\hline Interaction & & & & & Probability $\mathrm{P}$ & & \\
\hline Treatment $\times$ BW group & & & $<0.048$ & $<0.347$ & $<0.085$ & $<0.511$ & $<0.099$ \\
\hline \multicolumn{8}{|l|}{ Main effects } \\
\hline Treatment & & & $<0.022$ & $<0.001$ & $<0.064$ & $<0.085$ & $<0.602$ \\
\hline BW group & & & $<0.001$ & $<0.001$ & $<0.055$ & $<0.665$ & $<0.026$ \\
\hline
\end{tabular}

${ }^{1}$ A total of 1,092 pigs (PIC $359 \times$ Genetiporc F25 females; initial BW $=36.3 \mathrm{~kg}$ ) were used in a 117-d study to determine the influence of initial floor space allowance and removal strategy on growth performance. There were either 15 or 21 pigs per pen and 14 pens ( 7 barrow and 7 gilt pens) per treatment.

${ }^{2}$ Pigs initially provided $0.65 \mathrm{~m}^{2}$ of floor space were removed using 3 different strategies: 2:2:2 signifies pens where the 2 heaviest pigs on $\mathrm{d} 64,76$, and 95 were removed; 2:4 represents pens where the heaviest 2 pigs were removed on $\mathrm{d} 76$ and the 4 heaviest pigs were removed on d 105 ; and 6 represents pens where the heaviest 6 pigs were removed on $\mathrm{d} 105$.

${ }^{3}$ Pigs were ranked within pen as either light, medium, or heavy weight prior to each growth period for evaluation.

0.040) within-pen BW variation compared to pigs on the 6 removal strategy and pigs initially provided $0.91 \mathrm{~m}^{2}$ of floor space. After removals occurred on d 95, pigs remaining in pens on the 2:2:2 removal strategy had less $(P<0.024)$ within-pen BW variation than pigs initially provided $0.91 \mathrm{~m}^{2}$ of floor space or pigs on the $2: 4$ and 6 removal strategies. By d 105, prior to removals, pigs remaining in pens on the $2: 2: 2$ removal strategy had less $(P<0.016)$ within-pen $\mathrm{BW}$ variation than pigs initially provided $0.91 \mathrm{~m}^{2}$ of floor space or pigs on the 6 removal strategy. After removals occurred, all pigs in treatments initially providing $0.65 \mathrm{~m}^{2}$ had less $(P<0.005)$ withinpen $\mathrm{BW}$ variation compared to pigs initially provided $0.91 \mathrm{~m}^{2}$ of floor space. This was still evident on $\mathrm{d} 117$, when within-pen variation was greater $(P<0.003)$ for pens initially providing $0.91 \mathrm{~m}^{2}$ of floor space compared to pens initially providing $0.65 \mathrm{~m}^{2}$ of floor space.

DeDecker et al. (2005) concluded that BW variation within pen was reduced with the removal of the heaviest pigs, but the rate of reduction was dependent on the number of pigs removed and the time of measure after removals. Previous work by DeDecker et al. (2002) concluded that removing the heaviest $25 \%$ of the pen reduced within-pen BW variation, but by $21 \mathrm{~d}$ postremoval the BW variation was similar regardless of removal strategy. In the current study, it appeared that removing 2 pigs per pen, or approximately $10 \%$ of the pen, was successful at reducing within-pen BW variation, and the reductions in variation were still evident up to $19 \mathrm{~d}$ after the removals occurred. Interestingly, after removing 2 pigs from pens on the 2:4 removal strategy on $d 76$, within-pen variation was not reduced enough to be different from that of pens initially providing $0.91 \mathrm{~m}^{2}$ of floor space or pens on the 6 removal strategy (treatments without removals); this suggests that as BW increases, more pigs must be removed to significantly decrease the weight variation. Regardless, after all 6 pigs were removed from pens (approximately 30\% of the pen) on treatments initially providing $0.65 \mathrm{~m}^{2}$ of floor space, the $\mathrm{BW}$ variation within the pen was reduced below that of 
intact pens initially providing $0.91 \mathrm{~m}^{2}$. This information agrees with the previous reports of DeDecker et al. (2005) that within-pen BW variation is reduced when the heaviest pigs in a pen are removed but the degree of reduction is dependent on the number of pigs removed and their BW at time of removal.

\section{BW Categories within Pen}

From $\mathrm{d} 0$ to 64 , there was a BW category $\times$ treatment interaction $(P=0.048$; Table 8$)$ for ADG. This was due to a greater ADG in the heavy-weight pigs initially provided $0.91 \mathrm{~m}^{2}$ of floor space compared to heavy-weight pigs initially provided $0.65 \mathrm{~m}^{2}$ of floor space, whereas growth rates of the light- and medium-BW pigs were similar across initial floor space treatments. From a space standpoint it would be sensible to hypothesize that the heavier pigs in the pen would become limited on floor space before the lighter-weight pigs. The data set from the first growth period (d 0 to 64) supports that hypothesis; however, this warrants further investigation to understand if BW rank interacts with floor space allowance. From d 64 to 76, individual pig weights suggested no BW category $\times$ treatment interaction; however, light-weight pigs had lower $(P<0.001)$ ADG compared to mediumand heavy-weight pigs. From d 76 to 95 , there was a marginally significant $\mathrm{BW}$ group $\times$ treatment interaction $(P=$ 0.085 ) that was mainly the result of light-weight pigs in pens on the 2:4 removal strategy having lower ADG than light-weight pigs initially provided $0.91 \mathrm{~m}^{2}$ of floor space or light-weight pigs on the 2:2:2 removal strategy. No interaction of BW group $\times$ treatment or main effect of BW group was observed from d 95 to 105 , but from d 105 to 117 there was a marginally significant BW group $\times$ treatment interaction $(P=0.099)$ because light-weight pigs provided $0.91 \mathrm{~m}^{2}$ of initial floor space had lower ADG compared to light-weight pigs on other floor space and removal strategy treatments. Also, there was a BW group effect $(P=0.026)$ from d 105 to 117 because mediumBW pigs had the greatest ADG compared to light- and heavy-weight pigs within pens regardless of treatment.

\section{Economic Implications}

Total BW gain per pen was less $(P<0.001$; Table 9) for pens initially providing $0.91 \mathrm{~m}^{2}$ of floor space per pig compared to pens initially providing $0.65 \mathrm{~m}^{2}$ of floor space per pig. This was expected because there were fewer pigs per pen in pens initially providing $0.91 \mathrm{~m}^{2}$ of floor space. Alternatively, total weight gain per pig was greater $(P<0.001)$ for pigs initially provided $0.91 \mathrm{~m}^{2}$ of floor space compared to pigs initially provided $0.65 \mathrm{~m}^{2}$ of floor space. Additionally, weight gain per pig was less $(P=0.003)$ for pigs on the 2:2:2 removal strategy com- pared to pigs on the 6 removal strategy. Similar to total BW gain per pen, revenue expressed on a pen basis was less $(P<0.05)$ for pens initially providing $0.91 \mathrm{~m}^{2}$ of floor space because there were fewer pigs in the pen; however, when expressing the revenue on a pig basis, it was greater for pigs initially provided $0.91 \mathrm{~m}^{2}$ of floor space compared to pigs initially provided $0.65 \mathrm{~m}^{2}$ of floor space. Pigs on the 2:2:2 removal strategy had less $(P<0.001)$ revenue, either on a pen or pig basis, than pigs on the $2: 4$ and 6 removal strategies. Feed usage and feed cost per pen were less $(P<0.001)$ for pens initially providing $0.91 \mathrm{~m}^{2}$ of floor space compared to pens initially providing $0.65 \mathrm{~m}^{2}$ of floor space; however, per pig feed usage and feed cost were greater $(P<0.001)$ for pigs initially provided $0.91 \mathrm{~m}^{2}$ of floor space compared to pigs initially provided $0.65 \mathrm{~m}^{2}$ of floor space. Pigs in pens on the 2:2:2 removal strategy had less $(P<0.015)$ feed usage and reduced feed cost, either on a pen or pig basis, than pigs on the 2:4 and 6 removal strategies. Income over feed and facility cost was the least $(P<0.001)$, either on a pen or pig basis, for pigs initially provided $0.91 \mathrm{~m}^{2}$ of floor space. Pigs on the 2:2:2 removal strategy had less $(P<0.021)$ IOFFC when revenue was high and feed cost was low compared to pigs on the 6 removal strategy.

Powell et al. (1993) developed an economic model to determine the optimal stocking density for growing and finishing pigs and concluded that providing floor space below the requirement of pigs needed to achieve maximal ADG and ADFI was the most economic. The current study agrees with the previous work of Powell et al. (1993) indicating that providing enough space for pigs to achieve their maximum ADG was not the most economic. However, using removal strategies is beneficial to increase profitability. DeDecker et al. (2005) and Jacela et al. (2009) observed reductions in feed usage when removal strategies were utilized, and the same conclusion was derived in the present trial. Additionally, utilizing removal strategies reduces weight discounts associated with marketing pigs outside the specified packer weight range (Jacela et al., 2009). The study herein also illustrates that performing removals to provide the floor space allowance needed to reach maximum ADG (2:2:2) is still not economical because the weight of pigs that were removed is lighter than the specified packer weight range. The economic scenarios conclude that using the 2:4 and 6 marketing strategies is the most economic and that as feed cost increases and revenue decreases, the feed savings from the 2:4 marketing strategy are more profitable; alternatively, if revenue increases, keeping pigs within pens longer is more cost-effective. Therefore, this study concludes that improvements in ADG and ADFI can be achieved by pigs remaining in the pen following planned removals; however, it is important to consider the economic 
Table 9. The effects of initial floor space and removal strategy on economic parameters 1

\begin{tabular}{|c|c|c|c|c|c|c|}
\hline \multirow[b]{4}{*}{ Item } & \multicolumn{4}{|c|}{ Initial floor space, $\mathrm{m}^{2}$} & \multirow[b]{4}{*}{ SEM } & \multirow{4}{*}{$\begin{array}{c}\text { Probability } P \\
\text { initial } \\
\text { floor space }\end{array}$} \\
\hline & 0.91 & 0.65 & 0.65 & 0.65 & & \\
\hline & \multicolumn{4}{|c|}{ Marketing strategy $^{2}$} & & \\
\hline & None & $2: 2: 2$ & $2: 4$ & 6 & & \\
\hline Total weight gain, $\mathrm{kg} / \mathrm{pen}$ & $1,603^{\mathrm{b}}$ & $2,032^{\mathrm{a}}$ & $2,077^{\mathrm{a}}$ & $2,083^{\mathrm{a}}$ & 27.4 & $<0.001$ \\
\hline Total weight gain, ${ }^{4} \mathrm{~kg} / \mathrm{pig}$ & $110.1^{\mathrm{a}}$ & $99.8^{\mathrm{c}}$ & $103.1^{\mathrm{b}, \mathrm{c}}$ & $104.7^{\mathrm{b}}$ & 0.93 & $<0.001$ \\
\hline \multicolumn{7}{|l|}{ Revenue $^{5}$} \\
\hline Low, \$/pen & $1,705^{\mathrm{c}}$ & $2,177^{\mathrm{b}}$ & $2,247^{\mathrm{a}}$ & $2,281^{\mathrm{a}}$ & 10.6 & $<0.001$ \\
\hline High, \$/pen & $2,243^{\mathrm{c}}$ & $2,844^{\mathrm{b}}$ & $2,931^{\mathrm{a}}$ & $2,977^{\mathrm{a}}$ & 15.2 & $<0.001$ \\
\hline Low, ${ }^{6} \$$ pig & $113.69^{\mathrm{a}}$ & $103.65^{\mathrm{c}}$ & $106.98^{\mathrm{b}}$ & $108.64^{\mathrm{b}}$ & 0.51 & $<0.001$ \\
\hline $\mathrm{High},^{6} \$$ /pig & $149.55^{\mathrm{a}}$ & $135.45^{\mathrm{c}}$ & $139.57^{\mathrm{b}}$ & $141.78^{b}$ & 0.74 & $<0.001$ \\
\hline Feed usage, $\mathrm{kg} / \mathrm{pen}$ & $4,537^{\mathrm{c}}$ & $5,349^{\mathrm{a}}$ & $5,566^{\mathrm{b}}$ & $5,730^{\mathrm{b}}$ & 46.1 & $<0.001$ \\
\hline Feed usage, kg/pig & $307.7^{\mathrm{a}}$ & $269.5^{\mathrm{c}}$ & $282.8^{\mathrm{b}}$ & $292.4^{\mathrm{b}}$ & 2.75 & $<0.001$ \\
\hline \multicolumn{7}{|l|}{ Feed $\cos \mathrm{t}^{7}$} \\
\hline Low, \$/pen & $1,000^{\mathrm{c}}$ & $1,179^{\mathrm{b}}$ & $1,227^{\mathrm{a}}$ & $1,263^{\mathrm{a}}$ & 10.2 & $<0.001$ \\
\hline High, \$/pen & $1,300^{\mathrm{c}}$ & $1,533^{\mathrm{b}}$ & $1,595^{\mathrm{a}}$ & $1,642^{\mathrm{a}}$ & 13.2 & $<0.001$ \\
\hline Low, ${ }^{8} \$$ pig & $66.69^{\mathrm{a}}$ & $56.16^{\mathrm{c}}$ & $58.43^{\mathrm{b}}$ & $60.16^{\mathrm{b}}$ & 0.51 & $<0.001$ \\
\hline High, ${ }^{8}$ \$/pig & $86.70^{\mathrm{a}}$ & $73.01^{\mathrm{c}}$ & $75.97^{\mathrm{b}}$ & $78.21^{b}$ & 0.67 & $<0.001$ \\
\hline \multicolumn{7}{|l|}{ IOFFC,${ }^{9} \$ /$ pen } \\
\hline Low Rev-High Feed & $152.15^{\mathrm{b}}$ & $390.75^{\mathrm{a}}$ & $398.57^{\mathrm{a}}$ & $386.45^{\mathrm{a}}$ & 10.51 & $<0.001$ \\
\hline Low Rev-Low Feed & $452.25^{\mathrm{b}}$ & $744.50^{\mathrm{a}}$ & $766.71^{\mathrm{a}}$ & $765.45^{\mathrm{a}}$ & 8.94 & $<0.001$ \\
\hline High Rev-High Feed & $690.15^{\mathrm{b}}$ & $1058.59^{\mathrm{a}}$ & $1083.06^{\mathrm{a}}$ & $1082.37^{\mathrm{a}}$ & 11.93 & $<0.001$ \\
\hline High Rev-Low Feed & $990.15^{\mathrm{c}}$ & $1412.38^{\mathrm{b}}$ & $1451.19^{\mathrm{a}, \mathrm{b}}$ & $1461.37^{\mathrm{a}}$ & 11.48 & $<0.001$ \\
\hline \multicolumn{7}{|l|}{ IOFFC, ${ }^{9} \$$ pig } \\
\hline Low Rev-High Feed & $10.14^{\mathrm{b}}$ & $18.60^{\mathrm{a}}$ & $18.98^{\mathrm{a}}$ & $18.40^{\mathrm{a}}$ & 0.56 & $<0.001$ \\
\hline Low Rev-Low Feed & $30.15^{\mathrm{b}}$ & $35.45^{\mathrm{a}}$ & $36.51^{\mathrm{a}}$ & $36.45^{\mathrm{a}}$ & 0.47 & $<0.001$ \\
\hline High Rev-High Feed & $46.00^{\mathrm{b}}$ & $50.41^{\mathrm{a}}$ & $51.57^{\mathrm{a}}$ & $51.54^{\mathrm{a}}$ & 0.62 & $<0.001$ \\
\hline High Rev-Low Feed & $66.01^{\mathrm{c}}$ & $67.26^{\mathrm{b}, \mathrm{c}}$ & $69.10^{\mathrm{a}, \mathrm{b}}$ & $69.59^{\mathrm{a}}$ & 0.58 & $<0.001$ \\
\hline
\end{tabular}

${ }^{\mathrm{a}-\mathrm{c}}$ Means without a common superscript letter differ $(P<0.05)$.

${ }^{1}$ A total of 1,092 pigs (PIC $359 \times$ Genetiporc F25 females; initial BW $=36.3 \mathrm{~kg}$ ) were used in a 117-d study to determine the influence of initial floor space allowance and removal strategy on growth performance. There were either 15 or 21 pigs per pen and 14 pens ( 7 barrow and 7 gilt pens) per treatment.

${ }^{2}$ Pigs initially provided $0.65 \mathrm{~m}^{2}$ of floor space were removed using 3 different strategies: 2:2:2 signifies pens where the 2 heaviest pigs on $\mathrm{d} 64,76$, and 95 were removed; 2:4 represents pens where the heaviest 2 pigs were removed on d 76 and the 4 heaviest pigs were removed on d 105 ; and 6 represents pens where the heaviest 6 pigs were removed on d 105 .

${ }^{3}$ Initial floor space compares the mean of pigs initially provided 0.91 or $0.65 \mathrm{~m}^{2}$.

${ }^{4}$ Total weight gain per pig marketed.

${ }^{5}$ Revenue was based on a low $(\$ 0.99 / \mathrm{kg})$ or high $(\$ 1.32 / \mathrm{kg})$ base price. To mimic premium and discounts associated with specific carcass weights $(\mathrm{Cwt})$, a fixed yield of $75 \%$ was used to calculate HCW of pigs marketed, and the following regression equation was used to adjust premiums and discounts for varying HCW: premium/discount, $\$ / \mathrm{Cwt}, \mathrm{kg}=0.0001169532 \times \mathrm{HCW}^{3}-0.0516996146 \times \mathrm{HCW}^{2}+6.6397162094 \times \mathrm{HCW}-257.58240$.

${ }^{6}$ Revenue per pen divided by the initial placement of either 15 or 21 pigs per pen for pens initially stocked at 0.91 or $0.65 \mathrm{~m}^{2}$, respectively.

${ }^{7}$ Based on average diet costs of $\$ 220.46 / t$ for Low and $\$ 286.60 / t$ for High.

${ }^{8}$ Feed cost per pen divided by the initial placement of either 15 or 21 pigs per pen for pens initially stocked at 0.91 or $0.65 \mathrm{~m}^{2}$, respectively.

${ }^{9}$ Income over feed and facility costs: calculated as revenue - feed cost - facility cost. A fixed facility cost of $\$ 0.11$ per $0.69 \mathrm{~m}^{2} / \mathrm{d}$ was used to calculate facility costs.

implications of removal strategies to determine the most profitable strategy. In addition, the current study illustrates that the prediction equations developed by Gonyou et al. (2006) are useful predictors of the impact of floor space allowance on growth of finishing pigs but may underestimate the true impact of space restriction.

\section{LITERATURE CITED}

Augspurger, N. R., M. Ellis, and J. L. Beverly. 2000. The effect of removal of pigs from a group on growth performance and feed intake behavior of market weight pigs. J. Anim. Sci. 78(Suppl. 2):34. (Abstr.)

Bates, R. O., and M. D. Newcomb. 1997. Removal of market ready pen mates improved growth rate of remaining pigs. J. Anim. Sci. 75(Suppl. 1):247. (Abstr.)

Chapple, R. P. 1993. Effect of stocking arrangement on pig performance. In: E. S. Batterham, editor, Manipulating pig production IV. Australas. Pig Sci. Assoc., Attonwood, Victoria, Australia. p. 87. 
Cline, T. R., and B. T. Richert. 2001. Feeding growing-finishing pigs. In: A. Lewis and L. Southern, editors, Swine nutrition. 2nd ed. CRC Press, Boca Raton, FL. p. 718.

DeDecker, J. M., M. Ellis, B. F. Wolter, B. P. Corrigan, and S. E. Curtis. 2002. Effect of removing pigs from a pen at slaughter weight on the growth performance of the remaining animals. In: Proc. 2002 Br. Soc. Anim. Sci. Meet., York, UK.. p. 160.

DeDecker, J. M., M. Ellis, B. F. Wolter, B. P. Corrigan, S. E. Curtis, E. N. Parr, and D. M. Webel. 2005. Effects of proportion of pigs removed from a group and subsequent floor space on growth performance of finishing pigs. J. Anim. Sci. 83:449-454.

Gehlbach, G. D., D. E. Becker, J. L. Cox, B. G. Harmon, and A. H. Jensen. 1966. Effects of floor space allowance and number per group on performance of grow-finishing swine. J. Anim. Sci. 25:386-391.

Gonçalves, M. A. D., S. S. Dritz, M. D. Tokach, J. M. DeRouchey, J. C. Woodworth, and R. D. Goodband. 2016. Fact sheet: Feed efficiency adjustments to compare group close-outs in finishing pigs. J. Swine Health Prod. 24(4). 24(5):264-266

Gonyou, H. W., M. C. Brumm, E. Bush, J. Deen, S. A. Edwards, R. Fangman, J. J. McGlone, M. Meunier-Salaun, R. B. Morrison, H. Spoolder, P. L. Sundberg, and A. K. Johnson. 2006. Application of broken-line analysis to assess floor space requirements of nursery and grower-finisher pigs expressed on an allometric basis. J. Anim. Sci. 84:229-235.

Hamilton, D. N., M. Ellis, B. F. Wolter, A. P. Schinckel, and E. R. Wilson. 2003. The growth performance of the progeny of two sire lines reared under different floor space allowances. J. Anim. Sci. 81:1126-1135.

Hugh, W. I., and D. Reimer. 1967. Floor space allotment for growingfinishing pigs. J. Anim. Sci. 26:891. (Abstr.)

Jacela, J. Y., S. S. Dritz, M. D. Tokach, J. M. DeRouchey, R. D. Goodband, and J. L. Nelssen. 2009. Economic impact of removing pigs before marketing on the remaining pig's growth performance. Kansas Swine Ind. Day Rep. Prog. No. 1020. Kansas State University Agricultural Experiment Station, Manhattan, KS. p. 262-269.

Jensen, A. H., D. H. Baker, B. G. Harmon, and D. M. Woods. 1973. Response of growing-finishing male and female swine to floor space allowance on partially slotted and totally slotted floors. J. Anim. Sci. 37:629-631.
Moser, R. L., S. G. Cornelius, J. E. Pettigrew Jr., H. E. Hanke, and C. D. Hagen. 1985. Response of growing-finishing pigs to decreasing floor space allowance and(or) virginiamycin in diet. J. Anim. Sci. 61:337-342.

Myers, A. J., R. D. Goodband, M. D. Tokach, S. S. Dritz, J. M. DeRouchey, and J. L. Nelssen. 2012. The effects of feeder adjustment and trough space on growth performance of finishing pigs. J. Anim. Sci. 90:4576-4582. doi:10.2527/jas.2012-5389

NRC. 2012. Nutrient requirements of swine. 11th rev. ed. Natl. Acad. Press, Washington, DC.

Peterson, B. A. 2004. The effects of swine sire line, floor space, and sex on growth performance and carcass and meat quality characteristics of pigs. M.S. Thesis. Univ. of Illinois at UrbanaChampaign, Urbana.

Petherick, J. C., and S. H. Baxter. 1981. Modelling the static special requirements of livestock. In: Modelling, design and evaluation of agricultural buildings. Scott. Farm Build. Investig. Unit, Bucksburn, Aberdeen, UK. p. 75-82.

Potter, M. L., S. S. Dritz, M. D. Tokach, J. M. DeRouchey, R. D. Goodband, and J. L. Nelssen. 2010. Effects of increasing stocking density on finishing pig performance. Kansas Swine Ind. Day Rep. Prog. No. 1038. Kansas State University Agricultural Experiment Station, Manhattan, KS p. 216-222.

Powell, T. A., M. C. Brumm, and R. E. Massey. 1993. Economics of space allocation for grower-finisher hogs: A simulation approach. Rev. Agric. Econ. 15(1):133-141. doi:10.2307/1349717

Scroggs, L. V., H. G. Kattesh, J. L. Morrow, K. J. Stalder, J. W. Dailey, M. P. Roberts, J. F. Schneider, and A. M. Saxton. 2002. The effects of split marketing on the physiology, behavior, and performance of finishing swine. J. Anim. Sci. 80:338-345.

Thomas, L. L., R. D. Goodband, M. D. Tokach, J. M. DeRouchey, J. C. Woodworth, and S. S. Dritz. 2015. The effects of increasing stocking density on finishing pig growth performance and carcass characteristics. Kans. Agric. Exp. Stn. Res. Rep. 1(7):37.

Woodworth, J. C., S. S. Dritz, M. D. Tokach, R. D. Goodband, and J. L. Nelssen. 2000. Examination of the interactive effects of stocking density and marketing strategies in a commercial production environment. J. Anim. Sci. 78(Suppl. 2):56. (Abstr.) 